\title{
PENGARUH RENUMERASI DAN ETOS KERJA TERHADAP KINERJA PEGAWAI PADA BIRO UMUM SEKRETARIAT UTAMA BADAN PUSAT STATISTIK
}

\author{
Akhmad Junaedi \\ Institut Ilmu Sosial dan Manajemen STIAMI \\ $\underline{\text { stiami@ac.id \& kbskitbasa@yahoo.co.id }}$
}

\begin{abstract}
Abstrak. Masalah yang dihadapi oleh Biro Umum Badan Pusat Statistik adalah pemberian remunerasi yang menjadi ketergantungan pegawai serta Etos kerja yang masih rendah. Masalah tersebut menyebabkan kinerja pegawai tidak optimal. Penelitian ini menggunakan metode analisis kuantitatif dengan alat analisis regresi sederhana, dan regresi linier berganda Adapun teknik yang digunakan dalam penelitian ini untuk memperoleh data tentang, adalah sebagai berikut : Wawancara dan Angket / Quesioner. Populasi dari penelitian ini adalah seluruh pegawai pada Biro Umum Badan Pusat Statistik (BPS), yang berjumlah 100 orang termasuk Kepala Biro Umum. Teknik penarikan sampel secara sensus dengan sample random sampling dan hasil rumus yang digunakan untuk menentukan dan pengambilan sampel oleh Taro Yamane (dalam Riduwan, 2010:249). Analisis data menggunakan analisis regresi linier dengan menggunakan uji statistik SPSS untuk melihat pengaruh remunerasi dan etos kerja terhadap Kinerja Aparatur Sipil Negara (ASN) pada Biro Umum Badan Pusat Statistik pada tahun 2016, dengan signifikan 10\%.

Setelah melalui uji validitas dan reliabilitas data, diperoleh hasil yang menyatakan bahwa Remunerasi secara parsial berpengaruh Terhadap Kinerja pegawai. Demikian pula dengan Etos kerja berdasarkan penelitian menunjukkan berpengaruh signifikan terhadap kinerja pegawai. Berdasarkan hasil kajian dan penelitian secara bersama-sama Remunerasi dan Etos kerja berpengaruh positif dan signifikan Terhadap Kinerja Pegawai pada Biro Umum Badan Pusat Statistik. Biro Umum Badan Pusat Statistik. Persamaan regresinya adalah : $Y=22,917+0,123$ $\mathrm{X} 1+518 \mathrm{X} 2$, dimana setiap ada kenaikan 1 skor variabel X1 (renumerasi) dan X2 (etos kerja) akan meningkatkan Kinerja pegawai sebesar 0,123, dan 0,518, dengan asumsi variabel lainnya konstan,
\end{abstract}

Kata Kunci: Remunerasi, Etos kerja, Kinerja pegawai.

Abstract. The problem faced by the Central Bureau of Statistics is the remuneration that becomes the dependency of employees and the low work ethic. The problem causes employee performance is not optimal. This research uses quantitative analysis method with simple regression analysis tool, and multiple linear regression. The technique used in this research to obtain data about, is as follows: Interview and Questionnaire / Quesioner. The population of this study is all employees at the Central Bureau of Statistics (BPS), which amounts to 100 people including the Head of Public Bureau. Census sampling technique with sample random sampling and the result of formula used to determine and sampling by Taro Yamane (in Riduwan, 2010: 249). Data analysis using linear regression analysis using SPSS statistical test to see the effect of remuneration and work ethic on Performance of State Civil Apparatus (ASN) at General Bureau of Statistics Center in 2016, with significant $10 \%$.

After passing the validity and reliability of the data, obtained the result that states that Remuneration partially affect on employee performance. Similarly, work ethics based on research shows a significant effect on employee performance. Based on the results of the study and research together Remuneration and Working Ethics have a positive and significant impact on Employee Performance on the General Bureau of the Central Bureau of Statistics. Central Bureau of Statistics General Bureau. The regression equation is: $Y=22,917+0,123 X 1+518 X 2$, where every increase of 1 score of variable X1 (remuneration) and X2 (work ethic) will increase employee performance equal to 0,123, and 0,518, assuming other variable is constant,

Keywords: Remuneration, work ethic, Performance of employees. 
Akhmad Junaedi, Pengaruh Renumerasi Dan Etos Kerja Terhadap Kinerja Pegawai Pada Biro...

\section{PENDAHULUAN}

Sejak era Reformasi Birokrasi digulirkan dengan tujuan memperoleh perbaikan dalam hal pelayanan publik yang dilakukan oleh aparatur pemerintah atau Aparatur Sipil Negara (ASN). Pelayanan publik merupakan bagian dari kinerja pegawai, sehingga penyiapan dan penyajian data pada Biro pusat Statistik khususnya pada Biro umum terkait dengan pelayanan internal maupun eksternal seperti pengiriman dokumen, kearsipan, bidang pengadaan dan lain-pain sesuai dengan tugas pokoknya, merupakan bagian yang krusial terkait dengan kinerja pegawai, sehingga kinerja pegawai dari Biro Umum dapat mempengaruhi pengelolaan dan penyajian data yang dibutuhkan demi menunjang pemerintah dalam mengambil kebijakan dalam mendukung pembangunan nasional secara nasional. Dari hasil pengamatan atau obsevasi lapangan menunjukkan bukti bahwa kinerja Pegawai Negeri Sipil pada Biro Umum belum maksimal karena meskipun dengan menggunakan "finger print" pada saat datang, masih ada sebagian pegawai yang terlambat datang. Meskipun tidak terlambat datang namun setelah absen tidak langsung bekerja, namun mengobrol dengan rekan kerja yang lain, baca koran bahkan ada yang main game, atau bahkan ada yang langsung keluar kantor dengan alasan ada keperluan sebentar, kembali kekantor jam 10, bahkan sampai ada yang jam 12 siang.

Kondisi lain dari belum optimalnya kinerja pegawai adalah tidak tepat waktu dalam menyelesaikan pekerjaannya, (tidak tercapai target).

Sebagian dikalangan masyarakat berpendapat Penilaian DP3 hanya sekedar formalitas, bahkan nilai yang diberikan seringkali bergantung pada faktor-faktor individual pimpinan (subjektif). Unsur-unsur yang dijadikan dasar penilaian juga sangat sulit diukur keberhasilannya, apakah dari hasil kerja, kedisiplinan, etos kerja atau dari semua komponen kinerja yang tentunya tidak dapat diperoleh secara obyektif.

Akibatnya, hasil penilaiannya tidak mampu membedakan antara PNS yang berkinerja baik dengan yang berkinerja sebaliknya.

Tabel 1

Kondisi kinerja pegawai Biro Umum BPS berdasarkan nilai rata-rata DP3 tahun 2016

\begin{tabular}{|c|c|c|}
\hline Golongan & Rata-rata Nilai & Keterangan \\
\hline I & - & - \\
\hline II & 79,15 & Baik \\
\hline III & 83,65 & Baik \\
\hline IV & \multicolumn{2}{|}{} \\
\hline
\end{tabular}

Sumber: Data internal Biro k

Kepegawain yang telah diolah

Berdasarkan uraian di atas, penulis ingin mengetahui (1) Seberapa besar Remunerasi berpengaruh terhadap Kinerja pegawai; (2) Seberapa besar Etos kerja berpengaruh terhadap Kinerja pegawai serta (3) Seberapa besar remunerasi dan Etos kerja berpengaruh positif terhadap Kinerja pegawai pada Biro Umum Badan Pusat Statistik .

\section{KAJIAN TEORI}

\section{a. Teori Kinerja}

Kinerja merupakan pencapaian tujuan dari rencana pekerjaan dan mengorganisir langkah-langkah dalam mencapai tujuan tersebut dengan tenggat waktu yang diberikan (Goodman dan Svyantek, 1999 dalam Yusof et al.,2014). Sedangkan Kinerja pegawai pada dasarnya merupakan tingkat keberhasilan seorang pegawai selama periode tertentu dibandingkan dengan berbagai kemungkinan, seperti standar hasil kerja, target atau sasaran maupun kriteria yang ditentukan terlebih dahulu dan telah disepakati bersama. Kinerja merupakan hasil kegiatan yang telah dilakukan oleh pegawai atau suatu unit organisasi (Veitzal Rivai, 2004). Kinerja dikaitkan dengan kuantitas pekerjaan, kualitas pekerjaan, ketepatan waktu dalam bekerja, kehadiran / absensi pada pekerjaan, efisiensi dan efektifitas pekerjaan (Mathis \& Jackson 2009). Kinerja karyawan di dalam organisasi dipengaruhi oleh beberapa faktor antara lain yaitu renumerasi, etos kerja serta faktor-faktor lainnya, sebagaimana pendapat dari Fitriah dalam penelitiannya yang menyimpulkan bahwa peningkatan kinerja sumber daya manusia itu perlu memperhatikan gaji dan imbalan yang dikaitkan dengan prestasi dan tingkat produktivitasnya (Fitriah.2015:2). 
Peran SDM (Sumber Daya Manusia ) cukup besar dalam menentukan berhasilnya kegiatan sebuah organisasi. Tanpa adanya keterlibatan unsur manusia yang ada didalamnya kemungkinan besar tujuan organisasi yang diinginkan tidak akan tercapai termasuk pada organisasi publik khususnya pada Biro Umum Badan Pusat Statistik. Unsur pengelolaan atau manajemen ada dalam diri manusia sebagai bagian dari organisasi, sehingga pada akhirnya dibanding dengan faktor-faktor yang lain, maka manusia merupakan unsur yang paling menentukan keberhasilan atau kegagalan suatu organisasi dalam menyelenggarakan berbagai kegiatan, meskipun di era kemajuan teknologi sekalipun. Unsur SDM pada organisasi publik adalah pegawai yang diberikan tugas pokok dan fungsinya (tupoksi) yang harus dilaksanakan sesuai dengan Standar kerja sehingga melalui pelaksanaan tupoksinya diharapkan mampu memberikan kontribusi atas keberhasilan organisasi publik tersebut.

$$
\text { Sementara ini masyarakat }
$$

mempersepsikan bahwa jika berurusan dengan birokrasi cenderung lamban dalam memberikan pelayanan, tidak professional serta biaya mahal. Berbicara birokrasi tidak terlepas dari peraturan perudang-undangan ataupun peraturan pemerintah yang dibuat, namun persoalannya adalah terletak pada organ utamanya, yaitu Pegawai Negeri Sipil (PNS) atau Aparatur Sipil Negara (ASN) yang secara langsung sebagai Pelayan Publik yang harus melayani secara maksimal dan professional. Untuk mengatasi persoalan pelayanan publik yang kurang baik atau rendah telah dilakukan Reformasi Birokrasi. Dan pada tahun 2008 telah diterbitkan Grand Design reformasi birokrasi dalam bentuk Peraturan Menteri Pendayaan Aparatur Negara Nomor 15 tahun 2008 tentang Pedoman Umum Reformasi Birokrasi, yang merupakan cetak biru reformasi hingga tahun 2025.

Penilaian kerja melalui DP3 (daftar penilaian pelaksanaan pekerjaan) dibanyak lembaga pemerintahan yang dikeluarkan setiap tahun belum dapat dikatakan berhasil karena hanya 1 digunakan sebagai syarat kenaikan pangkat saja. Terkesan bahwa penilaian DP3 hanya sekedar formalitas, bahkan nilai yang diberikan seringkali bergantung pada faktor-faktor individual pimpinan (subjektif). Unsur-unsur yang dijadikan dasar penilaian juga sangat sulit diukur keberhasilannya. Akibatnya, hasil penilaiannya tidak mampu membedakan antara PNS yang berkinerja baik dengan yang berkinerja sebaliknya.

Badan Pusat Statistik merupakan salah satu lembaga pemerintah yang melaksanakan pelayanan publik. Badan Pusat Statistik adalah Lembaga Pemerintah Non Kementerian yang bertanggung jawab langsung kepada Presiden. Sebelumnya, BPS merupakan Biro Pusat Statistik, yang dibentuk berdasarkan UU Nomor 6 Tahun 1960 tentang Sensus dan UU Nomer 7 Tahun 1960 tentang Statistik. Sebagai pengganti kedua UU tersebut ditetapkan UU Nomor 16 Tahun 1997 tentang Statistik. Berdasarkan UU ini yang ditindaklanjuti dengan peraturan perundangan dibawahnya, secara formal nama Biro Pusat Statistik diganti menjadi Badan Pusat Statistik yang disingkat BPS. Tugas BPS adalah melaksanakan tugas pemerintahan dibidang statistik sesuai peraturan perundang-undangan, sedangkan fungsinya melakukan : pengkajian, penyusunan dan perumusan kebijakan dibidang statistik; pengkoordinasian kegiatan statistik nasional dan regional; penetapan dan penyelenggaraan statistik dasar; penetapan sistem statistik nasional; dan tugas lainnya.

Salah satu organisasi sebagai bagian dari BPS adalah Biro Umum yang secara struktural dibawah Sekretaris Utama. Biro Umum terdiri dari 4 (empat) bagian yaitu : a).Bagian Percetakan, Arsip dan Ekspedisi, b). Bagian Pengadaan Barang / Jasa, c).Bagian Inventarisasi penyimpanan dan penghapusan, d).Bagian Rumah Tangga. Biro Umum memiliki jumlah pegawai sebanyak 100 orang.

Persoalannya adalah dari jumlah 100 orang tersebut apakah telah melaksanakan tugas pokok serta fungsinya (Tupoksi) tidak ?, apakah reumerasi dan etos kerja mampu 
Akhmad Junaedi, Pengaruh Renumerasi Dan Etos Kerja Terhadap Kinerja Pegawai Pada Biro...

meningkatkan kinerja pegawai khususnya di Biro Umum Badan Pusat Statistik?.

\section{b. Teori Remunerasi}

Berdasarkan pendapat Hasibuan (2012 : 118) bahwa remunerasi merupakan semua pendapatan yang berbentuk uang,barang langsung atau tidak langsung yang diterima pegawai sebagai imbalan jasa yang diberikan kepada perusahaan.

Remunerasi yang adil merupakan sesuatu yang diterima karyawan sebagai bayaran dari kontribusi yang telah dilakukan untuk organisasi (Surya, 2009). Menurut Aswathappa (1997 dalam Sandilyan et al.,2012) menyatakan remunerasi adalah segala sesuatu yang diterima oleh karyawan sebagai balas jasa untuk kerja mereka. Dengan diberlakukannya pemberian remunerasi yang dirasakan adil bagi karyawan Biro Umum Badan Pusat Statistik, diharapkan dapat memotivasi karyawan untuk menjalankan tugasnya dengan berorientasi pada kinerja, memahami tentang apa yang menjadi tugas dan tanggung jawab masingmasing, serta target kinerja yang bagaimana yang harus dicapai.

Remunerasi pemerintahan merupakan bagian yang tidak terpisahkan dari kebijakan reformasi birokrasi. Dilatarbelakangi oleh kesadaran sekaligus komitmen pemerintah untuk mewujudkan clean and good governance. Remunerasi bermakna sangat strategik terhadap suksesnya reformasi birokrasi, mengingat dampak

paling nyata terhadap kinerja lembaga akan sangat ditentukan oleh perubahan kultur birokrasi didalam melaksanakan tugas pokoknya. Keberhasilan merubah kultur tersebut akan sangat ditentukan oleh tingkat kesejahteraan anggotanya.

Renumerasi yang sedianya diharapkan dapat menjadi alat untuk meningkatkan kinerja pegawai, namun masih banyaknya pegawai yang mencari cara bagaimana upaya tetap diberikan renumerasi dengan mengisi absen kehadiran tepat waktu, namun kemudian mencari kesempatan dan peluang memperoleh kegiatan diluar tugas pokoknya. Pemberian renumerasi disesuaikan dengan beberapa kriteria atau indikator, seperti halnya menurut Mondy, Noe (1993), dan Hasibuan (2007) dalam Sancoko (2010) mengemukakan beberapa indikator remunerasi sebagai berikut :

1. Nilai remunerasi dibanding dengan instansi pemerintah lainnya

2. Nilai remunerasi dibanding kinerja yang diberikan

3. Nilai remunerasi dibanding senioritas dalam daftar pegawai

4. Nilai remunerasi dibanding dengan pengalaman yang dimiliki

5. Nilai remunerasi dibanding level (grade yang dimiliki)

6. Nilai remunerasi dibanding potensi yang dimiliki.

7. Nilai remunerasi dibanding dengan kebutuhan yang harus dipenuhi.

Kurang optimalnya pelayanan dari Aparatur Sipil Negara pada Biro Umum dinilai lamban dalam menjalankan tugasnya dan tidak disiplin dalam mengemban kewajibannya disebabkan tingkat tanggung jawabnya terhadap masyarakat dalam penyajian data serta "sensitivitas" bidang kerja yang dilaksanakan yaitu antara lain menyiapkan pengiriman dokumen yang harus tepat waktu, mempersiapkan dan melaksanakan pengadaan barang yang dibutuhkan oleh Kantor Statistik diseluruh Indonesia dan lain-lain yang penanganannya harus cepat tepat dan sesuai dengan kebutuhan. Pengadaan barang sangat retan dengan isu timbulnya $\mathrm{KKN}$, sehingga tugas yang begitu berat harus disesuaikan dengan tingkat kesejahteraan para pegawai pada Biro tersebut.

Reformasi birokrasi dilakukan dalam bentuk penataan organisasi,prosedur kerja dan penentuan ukuranukuran keberhasilan kinerja. Adapun salah satu langkah untuk mereformasi birokrasi adalah dengan melaksanakan program remunerasi berbasis kinerja (performance based remuneration) dari kebijakan Menpan berupa Surat Edaran Menteri Pemberdayaan Aparatur Negara Nomor: SE/28/M.PAN/10/2004 Tanggal 10 Oktober 2004 tentang Penataan Pegawai Negeri Sipil (PNS).

Tunjangan kinerja atau remunerasi pegawai akan dibayarkan mengacu pada dua hal yaitu, 
disiplin kerja dan kinerja. Berdasarkan disiplin kerja sebagaimana diatur dalam Peraturan Pemerintah Nomor 53 tahun 2010 tentang Disiplin PNS. Selain itu berdasarkan kinerja sebagaimana diatur dalam Peraturan Pemerintah Nomor 46 tahun 2011 tentang Penilaian Prestasi Kerja PNS. Prinsip dasar remunerasi berbasis kinerja adalah adil dan proporsional. Kalau kebijakan masa lalu menerapkan pola sama rata (generalisir), sehingga dikenal adanya istilah PGPS (pintar goblok penghasilan sama), maka dengan kebijakan remunerasi berbasis kinerja, besar penghasilan (reward) yang diterima oleh seorang pegawai akan sangat ditentukan oleh bobot dan harga jabatan yang disandangnya serta kinerja yang telah dicapainya,(Sangadji, 2015:3).

Menurut Hasibuan, remunerasi merupakan komponen dari kesejahteraan yang diterima oleh pegawai, remunerasi bisa dijadikan sebagai unsur motivasi bagi pegawai untuk berprestasi (Hasibuan,2012:118). Pendapat tersebut menunjukkan bahwa seseorang yang berkinerja baik maka akan memperoleh imbalan yang lebih tinggi dan begitu pula sebaliknya. Artinya, semakin tinggi kinerja yang diraih pegawai akan semakin tinggi pula imbalannya. Menurut Dessler dalam Dharma (2010:30) mengemukakan bahwa remunerasi pegawai memiliki tiga komponen.

Ketiga komponen tersebut meliputi:

1) Pembayaran uang secara langsung (direct financial paymet),

2) Pembayaran tidak langsung (indirect payment), dan

3) Ganjaran non financial (nonfinasial rewards).

Penerapan sistem remunerasi Pegawai Negeri Sipil saat ini mengacu pada 5 Prinsip (Santoso, 2012), yaitu:

1. Sistem merit, yaitu penetapan penghasilan pegawai berdasarkan harga jabatan.

2. Adil, dalam arti jabatan dengan beban tugas dan tanggung jawab pekerjaan dengan bobot yang sama dibayar sama dan pekerjaan yang menuntut pengetahuan, keterampilan serta tanggung jawab yang lebih tinggi, dibayar lebih tinggi.
3. Layak, yaitu dapat memenuhi kebutuhan hidup layak (bukan minimal).

4. Kompetitif yaitu gaji PNS setara dengan gaji pegawai dengan kualifikasi yang sama di sektor swasta guna menghindari brain drain.

5. Transparan, dalam arti hanya memperoleh gaji dan tunjangan resmi

\section{c. Teori Etos Kerja}

Menurut Petty (2006 : 12), etos kerja memiliki tiga aspek atau karakteristik, yaitu keahlian interpersonal, inisiatif, dan dapat diandalkan. Sedangkan Sinamo (2010:56) menyederhanakannya menjadi empat pilar teori utama. Keempat pilar inilah yang sesungguhnya bertanggung jawab menopang semua jenis dan sistem keberhasilan yang berkelanjutan (sustainable success system) pada semua tingkatan.

Keempat elemen itu lalu dia konstruksikan dalam sebuah konsep besar yang disebutnya sebagai Catur Dharma Mahardika (bahasa Sanskerta) yang berarti Empat Darma Keberhasilan Utama, yaitu:

a. Mencetak prestasi dengan motivasi superior.

b. Membangun masa depan dengan kepemimpinanvisioner.

c. Menciptakan nilai baru dengan inovasi kreatif.

d. Meningkatkan mutu dengan keunggulan insani.

Keempat darma ini kemudian dirumuskan pada delapan aspek Etos Kerja sebagai berikut :

a. Kerja adalah rahmat.

b. Kerja adalah amanah.

c. Kerja adalah panggilan.

d. Kerja adalah aktualisasi.

e. Kerja adalah ibadah.

f. Kerja adalah seni.

g. Kerja adalah kehormatan.

h. Kerja adalah Pelayanan.

Berdasarkan pedapat Weber (dalam Sinamo, 2010: 117) ada beberapa faktor yang dapat mempengaruhi terbentuknya etos kerja, yaitu (a) Agama; (b) Budaya; (c) Sosial Politik; (d) Kondisi Lingkungan/Geografis; (e) 
Akhmad Junaedi, Pengaruh Renumerasi Dan Etos Kerja Terhadap Kinerja Pegawai Pada Biro...

Pendidikan; (f) Struktur Ekonomi dan (g) Motivasi Intrinsik Individu

\section{METODE PENELITIAN}

Dalam melakukan penelitian ni penulis menggunakan analisis deskriptif dengan desain asosiatif. Penelitian asosiatif disebut dengan penelitian hubungan sebab akibat. Tujuan yang diharapkan dari penelitian ini adalah "untuk mengetahui hubungan antara dua variabel atau lebih atau hubungan variabel bebas remunerasidan etos kerja dengan variabel terikat Kinerja pegawai.

Lokasi penelitian ini penulis lakukan pada Biro Umum . Alasan penulis memilih objek tersebut adalah dengan pertimbangan kesibukan yang dilakukan para pegawai atau Aparatur Sipil Negara (ASN) pada Biro Umum BPS dalam memberikan pelayanan yang tidak hanya kepada masyarakat, namun juga kepada Instansi lain dengan skala nasional, karena data yang diolah dan disajikan akan menjadi rujukan dan digunakan oleh pemerintah maupun swasta dalam memutuskan kebijakan maupun kegiata, usaha.

Populasi dari penelitian ini adalah seluruh pegawai pada Biro Umum Badan Pusat Statistik (BPS), yang berjumlah 100 orang termasuk Kepala Biro Umum. Teknik penarikan sampel secara sensus dengan sample random sampling dan hasil rumus yang digunakan untuk menentukan dan pengambilan sampel oleh Taro Yamane (dalam Riduwan, 2010:249).

Adapun teknik yang digunakan dalam penelitian ini untuk memperoleh data tentang, adalah sebagai berikut : Wawancara dan Angket / Quesioner. Analisis data menggunakan analisis regresi linier dengan menggunakan uji statistik SPSS untuk melihat pengaruh remunerasi dan etos kerja terhadap Kinerja Aparatur Sipil Negara (ASN) pada Biro Umum Badan Pusat Statistik pada tahun 2016, dengan signifikan $10 \%$.

Kemudian hasil data yang diperoleh akan dibandingkan (compare) dengan teori yang mendukung penelitian untuk memberikan kesimpulan maupun saran.

\section{HASIL PENELITIAN}

Badan Pusat Statistik (BPS) merupakan Instansi yang awal sejarahnya adalah didirikan oleh Direktur Pertanian dan Perdagangan (Directeur van Landbouw Nijverheid en Handel) dan berkedudukan di Bogor pada Februari 1920. Kemudian dalam perjalanan terakhirnya adalah sejak Agustus 1996, Soeharto, menetapkan tanggal diundangkannya UU No 7 tahun 1960 tentang Statistik tersebut sebagai "Hari Statistik" yang dilaksanakan secara nasional, dan pada tanggal 26 September dijadikan moment ulang tahun Badan Pusat Statistik. Badan Pusat Statistik (BPS) mempunyai struktur organisasi sebagai berikut pada Gambar 1 .

Sedangkan Biro Umum Badan Pusat Statistik berada dibawah Sekretaris Utama. Biro Umum mempunyai 4 (empat) bagian yaitu : 1). Bagian Percetakan, Arsip dan Ekspedisi yang membawahi a).subbagian percetakan dan penjilidan b). subabgian Arsip dan Ekpedisi. 2). Bagian Pengadaan barang dan jasa yang membawahi a).subbagian layanan pengadaan.b).subbagian pemantauan dan evaluasi pengadaan. 3). Bagian Inventarisasi, penyimpanan, penghapusan, yang membawahi a).subbag Inventarisasi, b).subbag penyimpanan, c).subbag penghapusan. 4). Bagian Rumah Tangga yang membawahi a).subbag urusan dalam dan pemeliharaan kantor, b).subbag pemeliharaan perlengkapan, c).subbag keamanan dan ketertiban.

Mayoritas responden Biro Umum BPS Tahun 2016 adalah laki-laki. Rata-rata respoden diperoleh sebagai berikut pada Tabel 2.

Tingkat pendidikan responden sebagian besar adalah SMA yaitu sebanyak 54 orang atau $0,54 \%$. Selebihnya S1 sebanyak 38 orang atau $0,38 \%$ dan S2 sebanyak 8 orang atau 0,08 \%. Masa kerja responden adalah rata2 diatas 5 tahun, sehingga memiliki pengalaman yang cukup.

Rekapitulasi jawaban responden sebagai berikut pada tabel 3 . 


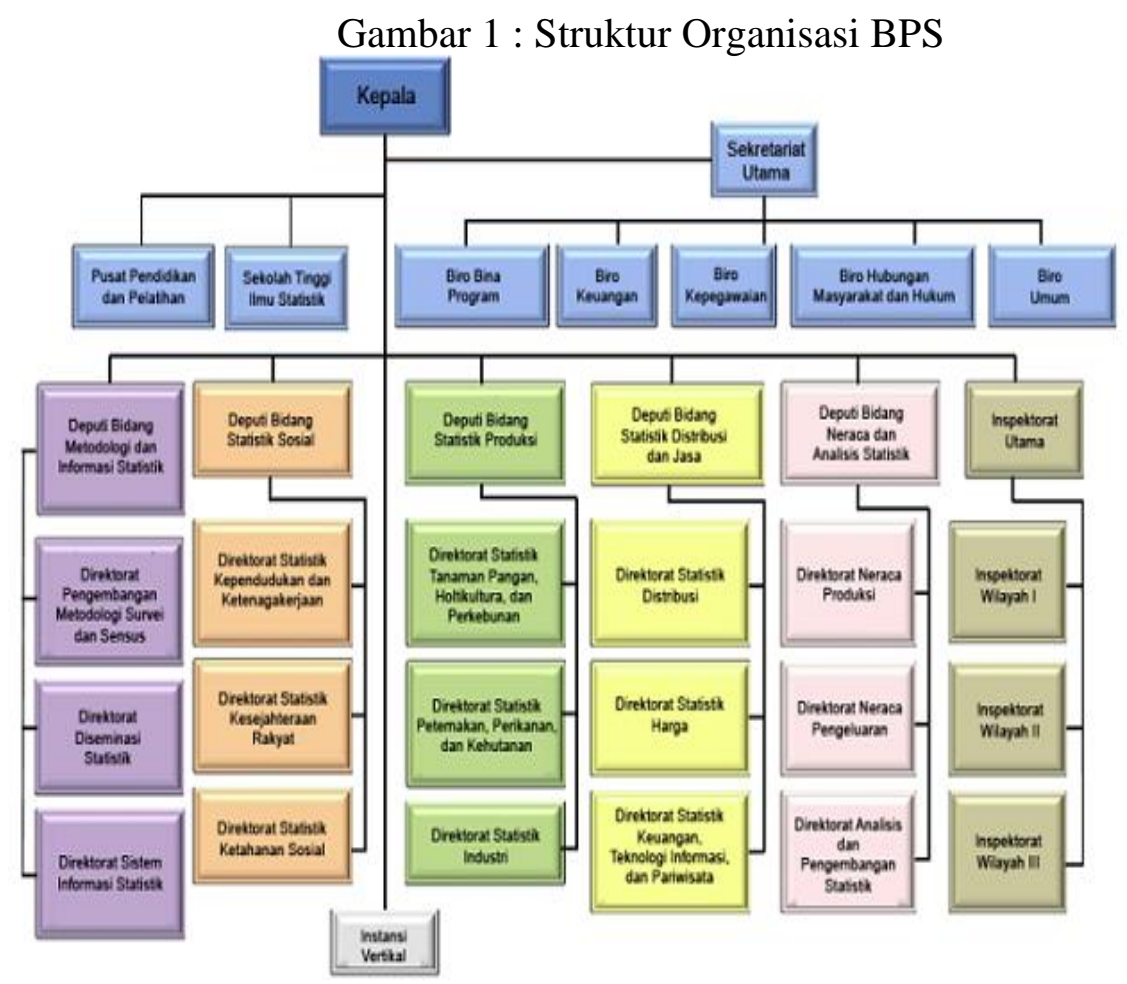

abel 2. Responden berdasarkan Usia

\begin{tabular}{|c|c|c|c|}
\hline No & Usia Responden & Jumlah & \% \\
\hline 1 & $20-25$ tahun & 24 & 0,24 \\
\hline 2 & $26-30$ tahun & 21 & 0,21 \\
\hline 3 & $31-35$ tahun & 29 & 0,29 \\
\hline 4 & $36-40$ tahun & 12 & 0,12 \\
\hline 5 & Diatas 40 tahun & 14 & 0,14 \\
\hline \multicolumn{2}{|c|}{ Total } & $\mathbf{1 0 0}$ & $\mathbf{1 0 0}$ \\
\hline
\end{tabular}

Sumber : Data Sekunder diolah.

Tabel 3. Rekapitulasi Jawaban Responden

\begin{tabular}{|c|c|c|c|c|c|c|c|c|c|c|c|c|c|}
\hline \multirow[b]{3}{*}{ No } & \multirow[b]{3}{*}{ Variabel } & \multicolumn{10}{|c|}{ Tanggapan Responden } & \multicolumn{2}{|c|}{ Total } \\
\hline & & \multicolumn{2}{|c|}{ SS } & \multicolumn{2}{|c|}{$S$} & \multicolumn{2}{|c|}{ RR } & \multicolumn{2}{|c|}{$\mathrm{TS}$} & \multicolumn{2}{|c|}{ STS } & \multirow[t]{2}{*}{ JR } & \multirow[t]{2}{*}{$\%$} \\
\hline & & JR & $\%$ & JR & $\%$ & JR & $\%$ & JR & $\%$ & JR & $\%$ & & \\
\hline 1 & Remunerasi & 36 & 0,36 & 34 & 0,34 & 16 & 0,16 & 10 & 0,10 & 4 & 0,04 & 100 & 100 \\
\hline 2 & Etos Kerja & 31 & 0,31 & 35 & 0,35 & 17 & 0,17 & 12 & 0,12 & 5 & 0,05 & 100 & 100 \\
\hline 3 & $\begin{array}{l}\text { Kinerja } \\
\text { pegawai }\end{array}$ & 33 & 0,33 & 38 & 0,38 & 20 & 0,20 & 9 & 0,09 & - & - & 100 & 100 \\
\hline & Rata-Rata & 33,3 & 33,3 & 35,6 & 35,6 & 17,8 & 17,8 & 10,3 & 10,3 & 3 & 0,03 & 100 & 100 \\
\hline
\end{tabular}

\section{Sumber data Sekunder diolah}

Keterangan :

- $\quad$ SS = Sangat Setuju, $S=$ Setuju, $R R=$ Ragu-ragu TS = Tidak Setuju STS=Sangat Tidak Setuju

- JR Jumlah responden 
Akhmad Junaedi, Pengaruh Renumerasi Dan Etos Kerja Terhadap Kinerja Pegawai Pada Biro...

Hasil penelitian dari pengujian regresi

1. Uji Validitas menunjukkan bahwa ketiga variabel (renumerasi,Etos kerja dan Kinerja pegawai) valid atau sesuai dengan kriteria menunjukkan bahwa :

kuesioner yaitu $100 \%$ terjawab seperti pada tabel case processing summary berikut :

Case Processing Summary

\begin{tabular}{|ll|r|r|}
\hline & & \multicolumn{1}{|c|}{$\mathrm{N}$} & \multicolumn{1}{c|}{$\%$} \\
\hline \multirow{4}{*}{ Cases } & Valid & 100 & 100,0 \\
& Excluded $^{\mathrm{a}}$ & 0 &, 0 \\
& Total & 100 & 100,0 \\
\hline
\end{tabular}

a. Listwise deletion based on all

variables in the procedure.

2. Uji reliabilitas menjunjukkan bahwa ketiga variabel dinyatakan reliabel karena nilai standar minimal 700 pada cronbach's alpha terpenuhi (angka reliabel 943), seperti disajikan pada tabel reliabilty statistics berikut :

\begin{tabular}{|c|c|c|}
\multicolumn{3}{c|}{ Reliability Statistics } \\
\hline \begin{tabular}{r|r|} 
Cronbac \\
h's
\end{tabular} & $\begin{array}{c}\text { Cronbac } \\
\text { h's }\end{array}$ & I of \\
Alpha & Items \\
& Alpha & \\
& Based & \\
& on & \\
& Standard & \\
& ized & \\
& Items & \\
\hline, 937 &, 943 & 3 \\
\hline
\end{tabular}

3. Uji t (regresi parsial) terhadap variabel bebas X1 (remunerasi) dengan hasil sebagai berikut : a. Terdapat pengaruh antara variabel X1 (remunerasi) terhadap Variabel terikat $\mathrm{Y}$ (Kinerja pegawai), karena $\mathrm{t}$ hitung $>\mathrm{t}$ tabel. Besarnya pengaruh adalah $62,8 \%$.

Model Summary ${ }^{b}$

\begin{tabular}{|l|c|r|r|r|c|}
\hline $\begin{array}{l}\text { Mo } \\
\text { del }\end{array}$ & $\mathrm{R}$ & $\begin{array}{c}\mathrm{R} \\
\text { Squar } \\
\mathrm{e}\end{array}$ & $\begin{array}{c}\text { Adjuste } \\
\mathrm{d} \mathrm{R} \\
\text { Square }\end{array}$ & $\begin{array}{c}\text { Std. Error } \\
\text { of the } \\
\text { Estimate }\end{array}$ & $\begin{array}{c}\text { Durbi } \\
\mathrm{n}- \\
\text { Watso } \\
\mathrm{n}\end{array}$ \\
\hline 1 &, $792^{\mathrm{a}}$ &, 628 &, 624 & 2,17691 & 1,728 \\
\hline
\end{tabular}

a. Predictors: (Constant), Remunerasi

b. Dependent Variable: Kinerja pegawai

Persamaan regresinya adalah : $\mathrm{Y}=$ $\mathrm{a}+\mathrm{b} 1 \mathrm{X} 1 \rightarrow \mathrm{Y}=22,04+0,653 \mathrm{X} 1$

Artinya bahwa setiap ada kenaikan 1 skor variabel $\mathrm{X} 1$ (renumerasi) akan mengakibatkan kenaikan Kinerja pegawai sebesar 0,653, dengan asumsi variabel lainnya konstan, seperti disajikan pada tabel coefficient berikut : 


Coefficients $^{\mathbf{a}}$
\begin{tabular}{|l|r|r|r|r|r|}
\hline Model & $\begin{array}{c}\text { Unstandard } \\
\text { ized } \\
\text { Coefficient } \\
\text { s }\end{array}$ & $\begin{array}{c}\text { Standar } \\
\text { dized } \\
\text { Coeffic } \\
\text { ients }\end{array}$ & t & Sig. \\
\cline { 2 - 4 } & B & $\begin{array}{r}\text { Std. } \\
\text { Erro } \\
\text { Beta }\end{array}$ & & \\
\hline $\begin{array}{l}\text { (Constan } \\
\text { t) }\end{array}$ & $\begin{array}{r}22,04 \\
\text { Remuner }\end{array}$ & $\begin{array}{r}2,99 \\
8\end{array}$ & & 7,35 &, 000 \\
asi &, 653 &, 051 &, 792 & $\begin{array}{r}12,8 \\
50\end{array}$ &, 000 \\
\hline
\end{tabular}

a. Dependent Variable: Kinerja pegawai

b. Terdapat pengaruh antara variabel X2 (etos kerja) terhadap Variabel terikat $\mathrm{Y}$
(Kinerja pegawai), karena $\mathrm{t}$ hitung $>\mathrm{t}$ tabel. Besarnya pengaruh adalah 71,8 \% . Model Summary ${ }^{b}$

\begin{tabular}{|l|c|c|r|c|c|}
\hline $\begin{array}{l}\text { Mod } \\
\text { el }\end{array}$ & $\mathrm{R}$ & $\begin{array}{c}\mathrm{R} \\
\text { Squar } \\
\mathrm{e}\end{array}$ & $\begin{array}{c}\text { Adjusted } \\
\mathrm{R} \\
\text { Square }\end{array}$ & $\begin{array}{c}\text { Std. } \\
\text { Error } \\
\text { of the } \\
\text { Estimat } \\
\mathrm{e}\end{array}$ & $\begin{array}{c}\text { Durbin } \\
\text { Watson }\end{array}$ \\
\hline 1 & $\begin{array}{r}, 847 \\
\mathrm{a}\end{array}$ &, 718 &, 715 & $\begin{array}{r}1,8949 \\
7\end{array}$ & 1,727 \\
\hline
\end{tabular}

a. Predictors: (Constant), Etos kerja

b. Dependent Variable: Kinerja pegawai

Persamaan regresinya adalah : $\mathrm{Y}=$ $\mathrm{a}+\mathrm{b} 2 \mathrm{X} 2 \rightarrow \mathrm{Y}=24,431+0,616 \mathrm{X} 2$

Artinya bahwa setiap ada kenaikan 1 skor variabel X2 (etos kerja) akan mengakibatkan kenaikan Kinerja pegawai sebesar 0,616, dengan asumsi variabel lainnya konstan. seperti disajikan pada tabel coefficient berikut :

\section{Coefficients $^{\mathrm{a}}$}

\begin{tabular}{|l|r|r|r|r|l|}
\hline Model & \multicolumn{2}{|c|}{$\begin{array}{c}\text { Unstandardized } \\
\text { Coefficients }\end{array}$} & $\begin{array}{c}\text { Stand } \\
\text { ardize } \\
\mathrm{d} \\
\text { Coeff } \\
\text { icient } \\
\mathrm{s}\end{array}$ & $\mathrm{T}$ & Sig. \\
& $\mathrm{B}$ & $\begin{array}{c}\text { Std. } \\
\text { Error }\end{array}$ & Beta & & \\
\cline { 2 - 5 } & 24,431 & 2,291 & & $\begin{array}{r}10,6 \\
65\end{array}$ &, 000 \\
\hline $\begin{array}{l}\text { (Const } \\
\text { ant }) \\
\begin{array}{l}\text { Etos } \\
\text { kerja }\end{array}\end{array}$ &, 616 &, 039 &, 847 & $\begin{array}{r}15,7 \\
87\end{array}$ &, 000 \\
\hline
\end{tabular}

a. Dependent Variable: Kinerja pegawai 
Akhmad Junaedi, Pengaruh Renumerasi Dan Etos Kerja Terhadap Kinerja Pegawai Pada Biro...

c. Terdapat pengaruh antara variabel X1 (renumerasi) dan X2 (etos kerja) secara bersama-sama terhadap Variabel terikat Y

(Kinerja pegawai), karena $\mathrm{t}$ hitung $>\mathrm{t}$ tabel. Besarnya pengaruh adalah 72,2\%.

\begin{tabular}{|l|r|r|r|r|r|}
\hline $\begin{array}{l}\text { Mod } \\
\text { el }\end{array}$ & $\mathrm{R}$ & $\begin{array}{c}\mathrm{R} \\
\text { Square }\end{array}$ & $\begin{array}{c}\text { Adjust } \\
\text { ed R } \\
\text { Square }\end{array}$ & $\begin{array}{c}\text { Std. } \\
\text { Error of } \\
\text { the } \\
\text { Estimate }\end{array}$ & $\begin{array}{l}\text { Durbin- } \\
\text { Watson }\end{array}$ \\
\hline 1 & $\begin{array}{r}85 \\
0^{\mathrm{a}}\end{array}$ &, 722 &, 716 & 1,89064 & 1,782 \\
\hline
\end{tabular}

a. Predictors: (Constant), Etos kerja,

Remunerasi

b. Dependent Variable: Kinerja pegawai

Persamaan regresinya adalah : $\mathrm{Y}=$ $\mathrm{a}+\mathrm{b} 1 \mathrm{X} 1+\mathrm{b} 2 \mathrm{X} 2 \rightarrow \mathrm{Y}=22,917+0,123$ $\mathrm{X} 1+518 \mathrm{X} 2$

Artinya bahwa setiap ada kenaikan 1 skor variabel X1 (renumerasi) dan X2 (etos kerja) akan meningkatkan Kinerja pegawai sebesar 0,123 , dan 0,518 , dengan asumsi variabel lainnya konstan, seperti disajikan pada tabel coefficient berikut :

\section{Coefficients $^{\mathrm{a}}$}

\begin{tabular}{|l|r|r|r|r|l|}
\hline Model & \multicolumn{2}{|c|}{$\begin{array}{c}\text { Unstandardi } \\
\text { zed } \\
\text { Coefficients }\end{array}$} & $\begin{array}{c}\text { Standar } \\
\text { dized } \\
\text { Coeffici } \\
\text { ents }\end{array}$ & T & Sig. \\
\cline { 2 - 4 } & \multicolumn{1}{|c|}{ B } & $\begin{array}{c}\text { Std. } \\
\text { Error }\end{array}$ & Beta & & \\
\hline $\begin{array}{l}\text { (Consta } \\
\text { nt) }\end{array}$ & 22,9 & 2,608 & & 8,78 &, 000 \\
$\begin{array}{l}\text { Remune } \\
\text { rasi }\end{array}$ &, 123 &, 102 &, 149 & 1,20 & 4 \\
$\begin{array}{l}\text { Etos } \\
\text { kerja }\end{array}$ &, 518 &, 090 &, 712 & 5,73 &, 000 \\
\hline
\end{tabular}

a. Dependent Variable: Kinerja pegawai

\section{PEMBAHASAN}

\section{a. Pengaruh Remunerasi Terhadap Kinerja pegawai Biro Umum Badan Pusat Statistik}

Berdasarkan hasil perhitungan dan uji $\mathrm{t}$ menunjukkan bahwa $\mathrm{t}$ hitung $>\mathrm{t}$ tabel untuk variabel bebas $\mathrm{X} 1$ (remunerasi), sehingga dengan demikian variabel remunerasi berpengaruh positif terhadap Kinerja pegawai pada Biro Umum Badan Pusat Statistik dengan pengaruhnya sebesar $62,8 \%$. Jika dikaitkan dengan penelitian dari Anharudin Azis' dan Fitrotun Niswah (2013) dalam penelitiannya yang berjudul : Pengaruh Renumerasi Terhadap Kinerja Pegawai Pada Kantor Pelayanan Pajak Pratama Tuban, dengan hasil penelitian menunjukkan bahwa Renumerasi mempunyai pengaruh sangat kuat terhadap Kinerja pegawai ada relevansi dan kesamaan, selaras dengan pendapat dari Fitriah yang mengatakan bahwa peningkatan kinerja sumber daya manusia itu perlu memperhatikan gaji dan imbalan yang 
dikaitkan dengan prestasi dan tingkat produktivitasnya (Fitriah.2015:2).

\section{b. Pengaruh Etos kerja Terhadap Kinerja pegawai Biro Umum Badan Pusat Statistik}

Hasil uji t pada variabel bebas $\mathrm{X} 2$ (Etos kerja) menunjukkan bahwa Etos kerja berpengaruh terhadap Kinerja pegawai karena $\mathrm{t}$ hitung $>\mathrm{t}$ tabel. Adapun besarnya pengaruh adalah $71,8 \%$.

Jika dikaitkan dengan penelitian dari Salsabil Maulidia Luthfia ; Abd. Qodir Djaelani dan Afi Rachmat Slamet (2017), penelitian yang diperoleh mendukung dan memperkuat penelitian yang dilakukan oleh Maulidia Luthfia dkk tersebut.

\section{c. Pengaruh Remunerasi Dan Etos kerja secara bersama-sama Terhadap Kinerja pegawai Biro Umum Badan Pusat Statistik}

Hasil analisis regresi melalui uji $\mathrm{F}$ memperoleh angka $\mathrm{F}$ hitung $>$ dari $\mathrm{F}$ tabel, sehingga dengan demikian dapat dikatakan bahwa Variabel bebas X1 berupa Remunerasi dan Variabel bebas X2 berupa Etos kerja secara bersama-sama berpengaruh terhadap Kinerja pegawai pada Biro Umum Badan Pusat Statistik, dengan nilai pengaruhnya adalah sebesar 72,2 \% dan hasil penelitian ini mendukung hasil penelitian terdahulu.

Implikasi dari hasil penelitian dapat digunakan oleh berbagai pihak dalam membuat berbagai kebijakan terkait dengan peningkatan kinerja pegawai melalui pemberian remunerasi yang sesuai dengan ketentuan serta peningkatan etos kerja pegawai dilingkungan Biro Umum Badan Pusat Statistik.

\section{KESIMPULAN DAN SARAN}

\section{Kesimpulan}

Dari hasil perhitungan serta analisis penelitian dengan menggunakan metode kuantitatif melalui regresi linier dapat disimpulkan bahwa : a. Secara parsial variabel bebas X1 (Remunerasi) berpengaruh positif dan signifikan terhadap Kinerja pegawai pada Biro Umum Badan Pusat Statistik yaitu sebesar $62,8 \%$.

b. Secara parsial variabel bebas X2 (Etos kerja) berpengaruh positif dan signifikan terhadap Kinerja pegawai pada Biro Umum BadanPusat Statistik yaitu sebesar $71,8 \%$.

c. Secara berganda atau bersama-sama variabel X1 (remunerasi) dan Variabel X2 (Etos kerja) berpengaruh positif dan signifikan Terhadap Kinerja pegawai pada Biro Umum Badan Pusat Statistik sebesar $72,2 \%$. Dengan demikian variabel atau faktor lain yang berpengaruh namun tidak diteliti yang disebut Epsilon $(\varepsilon)$ adalah sebesar 27,8 \%. Faktor-faktor tersebut antara lain : Motivasi kerja, disiplin pegawai, lingkungan kerja, profesionalisme, kompetensi, budaya organisasi, budaya kerja dan lain-lain.

\section{Saran}

Merujuk kesimpulan dari hasil penelitian, beberapa saran yang peneliti ajukan untuk memperkuat penelitian sebelumnya maupun penelitian yang dilakukan yaitu antara lain :

a. Kepada Pimpinan di lingkungan Biro Umum seperti para Kepala Bagian maupun Kepala Subbagian agar memberikan remunerasi berupa penghargaan, imbalan dan lain-lain agar sesuai dengan kapasitas dan prestasi pegawai.

b. Kepada Pimpinan agar mendorong pegawainya agar meingkatkan etos kerjanya mengingat tugas pokok dan fungsinya sangat diperlukan oleh Instansi internal (Kantor Statistik Provinsi/ kabupaten/kota) seperti halnya pengiriman barang yang dibutuhkan, pengaturan rumah tangga yang sesuai dengan kebutuhannya, bagian pengadaan barang maupun jasa yang dibutuhkan sesuai dengan Visi, Misi BPS yaitu mengolah 
Akhmad Junaedi, Pengaruh Renumerasi Dan Etos Kerja Terhadap Kinerja Pegawai Pada Biro...

dan menyajikan data untuk kepentingan Pemerintah maupun pihak swasta yang dibutuhkan dalam menyusun kebijakan.

c. Agar Pimpinan berlaku adil dalam hal pembinaan karir, dimana masih ada beberapa pegawai yang seharusnya sudah naik golongan atau jabatan karena pendidikan dan masa kerja yang lama, namun pimpinan selalu lebih mengutamakan lulusan dari Pendidikan Internal (STIS) sehingga masih ada beberapa pegawai dengan menyandang gelar Magister dan masa kerja lebih dari 25 tahun tidak diberikan kesempatan meningkatkan karirnya (Golongan pimpinan sama dengan stafnya) dimana atasannya masih Sarjana dengan masa kerja dibawah 10 tahun. Sehingga menimbulkan pegawai tersebut tidak dapat naik golongan sampai dengan pensiun alias Mentok.

d. Kepada pegawai agar lebih meningkatkan Kinerjanya, karena melalui penilaian kinerja akan memberikan kesempatan pegawai memperoleh remunerasi lebih besar tanpa dipotong, oleh karena remunerasi pada dasarnya adalah imbalan atau bentuk tunjangan kinerja yang diberikan atas dasar kedisiplinan kehadiran maupun pelaksanaan pekerjaan. Selain itu juga disarankan kepada pegawai agar meningkatkan etos kerjanya agar penilaian kinerjanya menjadi baik sehingga peluang karir dapat diperoleh dengan mudah.

\section{Daftar Pustaka}

\section{Buku-Buku :}

Petty, G. C. (2006). VocationalTehnical Education and The Occupational Work Ethic.Journal of Industrial Teacher Education

Priyatno Duwi. 2010. Paham Analisa Statistik Data dengan SPSS. Yogyakarta : Penerbit Mediakom.

Riduwan. 2010. Rumus dan Data Dalam Aplikasi Statitiska Untuk Penelitian : Administrasi Pendidikan, Bisnis,Pemerintahan, Sosial,Kebijakan,
Ekonomi, Hukum,Manajemen dan Kesehatan. Bandung : Penerbit Alfabeta.

Santoso, Urip. 2012. Remunerasi Pegawai Negeri Sipil.Diunduh dari http://uripsantoso.wordpress.com/2012/11 /03/remunerasi-pegawai- negeri-sipil/ Tanggal 13 April 2017

Sinamo, Jansen. 2010. Delapan Etos Kerja Profesional; Navigator Anda Menuju Sukses. Bogor : Grafika Mardi Yuana.

Sedarmayanti. 2009. Reformasi Administrasi

Publik, Reformasi Birokrasi, dan

Kepemimpinan Masa Depan

(Mewujudkan Pelayanan Prima dan Kepemerintahan yang Baik). Bandung : Refika Aditama.

\section{Dokumen :}

UU No 7 tahun 1960 tentang Statistik

Undang-Undang Republik Indonesia Nomor 5 Tahun 2014 Tentang Aparatur Sipil Negara.

Peraturan Pemerintah Republik Indonesia Nomor 30 Tahun 2015 tentang Perubahan Ketujuh Belas Atas Peraturan Pemerintah No 7 Tahun 1977 tentang Peraturan Gaji Pegawai Negeri Sipil

Peraturan Pemerintah Nomor 46 tahun 2011 tentang Penilaian Prestasi Kerja PNS.

Peraturan Pemerintah Nomor 53 tahun 2010 tentang Disiplin PNS.

Peraturan Pemerintah (PP) Nomor 42 tahun 2004 tentang Pembinaan Jiwa Korps dan Kode Etik PNS.

Peraturan Pemerintah Nomor 12 Tahun 2002 tentang kenaikan pangkat Pegawai Negeri Sipil

\section{Website :}

ASN. 2015. Terapkan Single Salary, Gaji PNS Minimal 4 Juta Tertinggi Bisa 57 Juta JOM FISIP Vol. 4 No. 2 - Oktober 2017 Page 14 http://www.asn-id.org update tanggal 10 Oktober 2017.

Salsabil Maulidia Luthfia , Abd. Qodir Djaelani, Afi Rachmat Slamet ; 2017 : Pengaruh Etos kerja, disiplin kerja dan Komitmen Organisasi Terhadap Kinerja Pegawai Kantor Kementerian Agama Kota Batu. 